\title{
A review of the literature on HIV infection and schizophrenia: implications for research, policy and clinical practice
}

\author{
RICHARD GRAY ${ }^{1}$ RN PhD, ELIZABETH BREWIN ${ }^{2}$ RN BSC(Hons), JAMES NOAK ${ }^{3}$ \\ RN RMN cert HSM cert Health Econ mSc mHSM, JANELLE WYKE-JOSEPH ${ }^{4}$ \\ B ABITA SONIK ${ }^{4}$ \\ ${ }^{1}$ MRC Fellow in Health Services Research, ${ }^{2}$ Research Nurse, ${ }^{3}$ Robert Baxter Research Fellow and ${ }^{4}$ Research Worker, \\ Health Services Research Department, Institute of Psychiatry, London, UK
}

\author{
Correspondence: \\ Richard Gray \\ Health Services Research \\ Department \\ Institute of Psychiatry \\ De Crespigny Park \\ London SE5 8AF \\ $U K$ \\ E-mail:R.Gray@iop.kcl.ac.uk
}

\section{GRAY R., BREWIN E., NOAK J., WYKE-JOSEPH J. \& SONIK B. (2002) Journal of} Psychiatric and Mental Health Nursing 9, 405-409

\section{A review of the literature on HIV infection and schizophrenia: implications for research, policy and clinical practice}

\begin{abstract}
AIDS represents one of the major public health problems of the 21st century. Men having sex with men, injecting drug use and having multiple sexual partners are well-established risk behaviours for transmitting the HIV virus. People with schizophrenia are more likely to engage in these behaviours than the general population and as a result there is an increased prevalence of HIV infection in this group. However, many contemporary mental health policy reports fail to discuss the risk of HIV/AIDS in people with schizophrenia, and there are few specific references to sexual health promotion in these documents. People with schizophrenia should be considered an at-risk population for HIV infection and other sexually transmitted diseases. Psychiatric research, policy and clinical practice need to develop rapidly to address this important aspect of a major public health problem.
\end{abstract}

Keywords: AIDS, HIV, policy, practice, schizophrenia, sexual health

Accepted for publication: 8 March 2002

\section{Background}

The human immunodeficiency virus (HIV) infection epidemic represents one of the most serious public health problems of modern times. Since the onset of the pandemic at least 21.8 million people have died from acquired immunodeficiency syndrome (AIDS) and at least 36 million are living with HIV infection/AIDS (WHO 2000). In 1999 world-wide, 5.3 million people were newly infected with the virus. Historically, epidemiological studies have shown that intravenous drug users and men who have sex with men (MSM) were most at risk of HIV infection. However, in the last few years there has been an increase in the proportion of people with HIV infection where transmission was through other risk behaviours. In most countries there has been considerable effort to increase public awareness of the HIV problem through preventative educational campaigns (Di Clemente \& Peterson 1994). However, scant attention has been paid to people with schizophrenia, an already vulnerable and disenfranchised section of the community, who should rightly be considered a population at high risk of HIV infection (Grassi et al. 1999).

In the year 2000, the prevalence of HIV infection among the adult population aged $15-49$ years was $0.11 \%$ in Britain and $0.35 \%$ in western Europe (WHO 2000). The main mode of transmission in both Britain and western Europe was through men having sex with men (WHO 2000). Recent research in the United States of America (USA) has shown alarmingly high rates of HIV seropositivity among people with serious and enduring mental disorders (of which the majority have schizophrenia), ranging from $9 \%$ to $19 \%$ (Cournos et al. 1991, Volavka et al. 1991, Susser 
et al. 1993, Silberstein et al. 1994). The few prevalence studies that have been conducted in western Europe also show an increased prevalence rate of around $5 \%$ in people with schizophrenia (Naber et al. 1994, Ayuso-Mateos et al. 1997). These prevalence figures suggest that around $2 \%$ (4000-5000) of people with schizophrenia in the United Kingdom (UK) are currently living with AIDS/HIV.

Perhaps the most important observation in the prevalence studies was that clinicians working with people with schizophrenia were unaware of the increased risk of HIV/ AIDS in this population and made little effort to screen patients for seropositivity, possibly because of ethical issues surrounding the ability to gain informed consent, and the lack of available pre- and post-test counselling (Cournos et al. 1991). This is alarming because once a patient tests positive for HIV risk-taking behaviours can be addressed and treatment started. This finding suggests that HIV/AIDS is not being well managed in this population and because treatment is delayed people with schizophrenia who are HIV positive are likely to have a worse outcome than the general population. The poor HIV-positive detection rate may also be explained by a widely held belief among clinicians that people with schizophrenia do not have sex. For example, Akhtar \& Thomson (1980) observed that initially people with schizophrenia have an increase in sexual activity that lessens over the course of the illness, frequently resulting in marked hyposexuality. If this is true, then clinicians may perceive that promoting sexual health in their patients is a fairly low priority. However, the prevalence of HIV in this group compared with the general population suggests that people with schizophrenia may be sexually active and engaging in risky sexual practices and/or injecting drugs.

\section{Do people with schizophrenia have sex?}

It has long been recognized that people with schizophrenia have lower reproduction rates than the general population (Nimgaonkar et al. 1997). Sexual disinterest and dysfunction have been attributed to both the disorder and the side-effects of antipsychotic medication (Gray 1999). High rates of depression have also been observed in people with schizophrenia (associated with a loss of interest in sex; Gotesman \& Groome 1997) and psychotic symptoms such as delusions and hallucinations may make it difficult for people with schizophrenia to form and maintain lasting relationships. These problems do not, however, eliminate the desire for sexual contact (McEvoy et al. 1983) or leave people sexually inactive (Kelly et al. 1992).

Contrary to the prevailing clinical stereotypes, people with schizophrenia (at least in America) are sexually active (Cournos et al. 1994). For example, Cournos et al. (1994) found that $44 \%$ of people with schizophrenia had been regularly sexually active in the previous 6 months. The frequency of sexual activity in psychiatric inpatients and controls was compared in a study by McDermot et al. (1994), who found no difference between the groups. Each group reported an average of 11 sexual contacts in a typical month.

\section{Risk behaviours}

People with schizophrenia, who have sex, do appear to be more likely to engage in known high-risk sexual behaviours. In a study by Cournos et al. (1994) condom use was very low (around $8 \%$ ), drug or alcohol use during sex was common, as was sexual exchange (for money, drugs or other goods). Patients often had multiple sexual partners and around $12 \%$ of those who were sexually active had sex with a partner who was a known injecting drug user. Anal sex appeared to be common among people with schizophrenia (around 11\%), although the majority of men who had sex with men did not classify themselves as being gay. Finally, research in the UK has established that around a third of people with schizophrenia have a substance misuse problem; although injecting drug use is rare (around 1$2 \%)$, those who do, tend to use contaminated equipment and share needles (Wright et al. 2000). It is widely accepted that the risk behaviours for HIV infection are anal sex, infected intravenous injecting equipment, sex with intravenous drug users and MSM (Centres for Disease Control \& Prevention 1995). As people with schizophrenia are more likely to engage in these activities, this may begin to explain the high rate of seroprevalence in this population.

\section{HIV/AIDS awareness}

American research seems to suggest that the level of HIV awareness among people with schizophrenia is substantially lower than in the general population. For example, Aruffo et al. (1990) found that women with schizophrenia knew significantly less about HIV and how it was transmitted than a control group. Structured interviews were used by Kalichman et al. (1994) to test knowledge about HIV in 95 psychiatric outpatients (82\% had schizophrenia). Important deficits in knowledge were reported. For example, $37 \%$ believed that showering after sex can prevent you from getting HIV, $26 \%$ thought that a person must have multiple sexual partners to get the virus and $24 \%$ reported that a person who got the HIV virus from injecting drugs could not transmit the virus to someone else by having sex. Kelly et al. (1992) used a questionnaire to assess knowledge of HIV risk behaviour among 60 patients with chronic mental illnesses (70\% had schizophrenia) and 
again knowledge was poor. For example, $53 \%$ believed that most people become sick quickly after getting the HIV virus, just under half reported that people who can give you the HIV virus always look sick and around a third of respondents stated that only MSM get AIDS.

It is important to be cautious when generalizing American research to the UK. However, as there are no published studies undertaken in the UK, it is reasonable to propose, at least as a testable hypothesis, that there are similar deficits in knowledge about HIV/AIDS among people with schizophrenia living in Britain. The deficits in knowledge are surprising, given the massive multimedia, public education programmes in both the UK and America since the 1980s. It is possible that some of the symptoms of schizophrenia, especially the effects on cognitive functioning and disordered thought processes, are barriers to effective HIV/AIDS awareness. This may explain why the prevalence of HIV infection is higher in people with schizophrenia. These findings may also indicate that information needs to be presented in a different way and that interventions that have been shown to be effective in the general population may not automatically be translated for use with people with schizophrenia.

\section{Health behaviour change}

In the general adult population, it is clear that simply giving people information about HIV/AIDS, at least on its own, does not change behaviour (Angleton 1989, Greenblat et al. 1989). So called 'fear-arousal', as seen in the early mass media campaigns on AIDS, is similarly generally ineffective (Sherr 1989). The same appears to be true among people with schizophrenia. For example, McKinnon et al. (1996) found no reduction in HIV risk behaviour among patients with greater knowledge about AIDS.

Interventions that appear to be effective in changing behaviour in the general population include those that address patients' health beliefs and help people develop new skills, such as negotiating condom use (Aggleton 1997, Stoller \& Rutherford 1989). However, the impact of health beliefs on people with schizophrenia may be different from the general population. For example, McDermott et al. (1994) showed that different factors predicted changes in sexual behaviour among people with schizophrenia and healthy controls. In controls, a combination of AIDS knowledge, perceptions of behavioural control and perceived control over sexual thoughts and behaviour, predicted changes in high-risk behaviour. Changes in the sexual behaviour of people with schizophrenia, by contrast, were associated with perceptions of cognitive control, a belief that one can reduce one's risk of AIDS by changing one's behaviour, and a belief in the future development of treatment for AIDS. These results emphasize the need to develop, or at least tailor, interventions to meet the different needs and beliefs of people with schizophrenia.

Three American randomized controlled trials have used these ideas to develop targeted interventions for people with schizophrenia and have produced promising results (Kalichman et al. 1995, Kelly 1997, Weinhardt et al. 1998). For example, Kalichman et al. (1995) gave patients four 90-minute behavioural skills training sessions that resulted in a significant reduction in unsafe sexual practices.

\section{Current practice}

The available evidence strongly suggests that people with schizophrenia are at an increased risk of HIV infection and have important deficits in their understanding about the disease. Despite this body of evidence, mental health professionals in the UK appear to fail in the detection of patients who are HIV positive, and generally do little to promote the sexual health of their patients (Cournos et al. 1991, Park Dorsey \& Forchuk 1994).

According to Firn (1997) many mental health professionals avoid discussing sexual health issues (and consequently HIV/AIDS) because of a fear of appearing to encourage or condone sexual expression in whatever form. This prevailing attitude is perhaps a consequence of the 'no sex' policy that exists in many psychiatric hospitals, presumably to protect vulnerable patients. These policies often state that sex on the wards or in the hospital is strictly forbidden. However, as has already been established, patients are sexually active. As a result fairly obvious sexual health interventions, such as providing condoms to patients free of charge, potentially reducing the risk of HIV transmission, cause great debate among mental health professionals. Some are concerned that the provision of condoms or the discussion of sexual issues will lead to an increase in sexual activity.

\section{Mental health policy and HIV}

The National Service Framework for Mental Health (Department of Health 2000) makes no mention of sexual health. Neither do two recent reports looking at problems in acute psychiatric inpatient care: Addressing Acute Concerns (Standing Nursing and Midwifery Advisory Committee 2000) and Acute Problems (Sainsbury Centre for Mental Health 1998). The sexual health policies of many mental health NHS Trusts are hopelessly out of date, many simply stating that psychiatric inpatients are not allowed to have sex whilst an inpatient (Firn 1997). One policy from a south London mental health Trust states that: 'Sexual 
activity involving patients on hospital premises is not an acceptable form of behaviour'.

\section{Considerations for research, policy and clinical practice}

It seems highly likely that people with schizophrenia in the UK are at an increased risk of HIV infection because they engage in high-risk behaviours, most notably men having sex with men. Psychiatric research, policy and clinical practice have failed to adequately address the problem and as a result people have, avoidably, become infected with the HIV virus. In the UK, research, policy and clinical practice need to develop rapidly and in parallel to address this problem. There is an urgent need to establish the prevalence of HIV infection among people with schizophrenia throughout the UK. It is then necessary to understand the mode of transmission in these individuals and their understanding and beliefs about HIV/AIDS. These data can be used to develop and/or refine interventions to change the behaviour of people with schizophrenia and then inform policy and clinical practice.

Mental health policy and practice cannot wait for the results of studies that may take many years to complete. Policy makers need to consider the sexual health (and expression) of people with schizophrenia as an important part of their overall health. The inclusion of harm reduction interventions (such as the availability and supply of condoms) and the early detection of HIV-positive status as part of national and local policy is a critical first step. Changing the clinical practice of mental health professionals presents a substantial challenge. It is unlikely that research and policy will, at least in the short term, impact on the care and treatment that patients receive. The only effective method of changing clinical practice is training (Gray 2001). However, training is expensive and time consuming and careful consideration would need to be given to how an effective training intervention could be disseminated rapidly throughout the NHS.

\section{Conclusion}

HIV infection in people with schizophrenia is a serious but largely ignored part of the HIV epidemic. People with schizophrenia should be considered to be an at-risk population who warrant special attention. Much could be done in terms of research, policy and clinical practice, especially developing, testing and implementing methods of improving early detection of HIV-positive status and simple riskreduction strategies. However, mental health professionals appear reluctant to talk about sexual health and until they do, people will continue to become infected.

\section{References}

Akhtar S. \& Thomson J.A. (1980) Schizophrenia and sexuality: a review and a report of twelve unusual cases, Part II. Journal of Clinical Psychiatry 41, 166-174.

Aggleton P. (1997) Behaviour change communication strategies. AIDS Education and Prevention 9 (2), 111-123.

Angleton P. (1989) Evaluating health education about AIDS. In: AIDS Social Representations, Social Practices (eds Aggleton P et al.), pp. 106-107. Falmer Press, Basingstoke.

Aruffo J., Coverdale J., Chacko R. (1990) Knowledge about AIDS among women psychiatric outpatients. Hospital and Community Psychiatry 41, 326-328.

Ayuso-Mateos J.L., Montanes-Lastra I., De La Garza P.J. \& Ayuso-Gutierrez J.L. (1997) HIV infection in psychiatric patients: an unlinked anonymous study. British Journal of Psychiatry 170, 181-185.

Centres for Disease Control and Prevention (1995) HIV/AIDS Surveillance Report 7. Centres for Disease Control and Prevention, Atlanta, Georgia.

Cournos F., Empfield M., Horwath E., McKinnon K., Meyer I., Schrage H. et al. (1991) HIV seroprevalence among patients admitted to two psychiatric hospitals. American Journal of Psychiatry 148 (9), 1225-1230.

Cournos F., Guido J.R., Coomaraswamy S., Meyer-Bahlburg H., Sugden R. \& Howath E. (1994) Sexual activity and risk of HIV infection among patients with schizophrenia. American Journal of Psychiatry 151 (2), 228-232.

Department of Health (2000) Modern Standards and Service Models. Mental Health. Department of Health, London.

Di Clemente R.J. \& Peterson S. (1994) Preventing AIDS. Theories and Methods of Behavioural Intervention. Plenum Press, New York.

Firn S. (1997) Key issues in sexual health. In: Stuart and Sundeens' Mental Health Nursing Principles and Practice (eds Thomas B. et al.), pp. 416-421. Mosby, London.

Gotesman I.I. \& Groome C.S. (1997) HIV/AIDS risks as a consequence of schizophrenia. Schizophrenia Bulletin 23 (4), 675684.

Grassi L., Pavanati M. \& Cardelli R. (1999) HIV-risk behaviour and knowledge about HIV/AIDS among patients with schizophrenia. Psychological Medicine 29 (1), 171-179.

Greenblat C., Katz S., Gagnon J.H. \& Shannon D. (1989) An innovative programme of counselling family members and friends of seropositive haemophiliacs. AIDS Care 1 (1), 67-75.

Gray R. (1999) Antipsychotics, side effects and effective management. Mental Health Practice 2 (7), 14-20.

Gray R. (2001) A randomised controlled trial of medication management training for CPNs. PhD thesis, Institute of Psychiatry, Kings College, London.

Kalichman S.C., Sikkema K.J., Kelly J.A. \& Bulto M. (1994) Factors associated with risk for HIV infection among chronic mentally ill adults. American Journal of Psychiatry 15 (1), 221-227.

Kalichman S.C., Sikkema K.J., Kelly J.A. \& Bulto M. (1995) Use of a brief behavioural skills intervention to prevent HIV infection among chronic mentally ill adults. Psychiatric Services 46, 275-280.

Kelly J.A., Murphy D.A., Bahn G.R., Brasfield T.L., Davis D.R., Hauth A.C. et al. (1992) AIDS/HIV risk behaviour among the chronic mentally ill. American Journal of Psychiatry 149 (7), 886-889. 
Kelly J.A. (1997) HIV risk reduction intervention for persons with severe mental illness. Clinical Psychology Review 17 (3), 293309.

McDermott B.E., Sautter F.J., Winstead D.K. \& Quirk T. (1994) Diagnosis, health beliefs, and risk of HIV infection in psychiatric patients. Hospital and Community Psychiatry 45 (6), 580585 .

McEvoy J.P., Hatcher A., Appelbaum P.S. \& Abernethy V. (1983) Chronic schizophrenic women's attitudes toward sex, pregnancy and childrearing. Hospital and Community Psychiatry 34, 536-539.

McKinnon K., Cournos F., Sugden R., Guido J.R. \& Herman R. (1996) The relative contributions of psychiatric symptoms and AIDS knowledge to HIV risk behaviours among people with severe mental illness. Journal of Clinical Psychiatry 57 (11), 506-513.

Naber D., Paj onk F.G., Perro C. \& Lohmer B. (1994) Human immunodeficiency virus antibody test and seroprevalence in psychiatric patients. Acta Psychiatrica Scandinavica 89, 358361.

Nimgaonkar V.L., Ward S.E., Agarde H., Weston N. \& Ganguli R. (1997) Fertility in schizophrenia: results from a contemporary US cohort. Acta Psychiatrica Scandinavica 95 (5), 364369.

Park Dorsey J. \& Forchuk C. (1994) Assessment of the sexuality needs of individuals with psychiatric disability. Journal of Psychiatric and Mental Health Nursing 1, 93-97.

Sainsbury Centre for Mental Health (1998) Acute Problems. The Sainsbury Centre, London.
Sherr L. (1989) Health education. AIDS Care 1 (2), 188-192.

Silberstein C., Galanter M., Marmor M., Lifshutz H., Krasinski K. \& Franco H. (1994) HIV-1 among inner city dually diagnosed inpatients. American Journal of Drug and Alcohol Abuse 20, 201-213.

Stoller E.J. \& Rutherford G.W. (1989) Evaluation of AIDS prevention and control programs. AIDS 3 (Suppl. 1), S289S296.

Standing Nursing and Midwifery Advisory Committee (2000) Addressing Acute Concerns. SNMAC, London.

Susser E., Valencia E. \& Conover S. (1993) Prevalence of HIV infection among psychiatric patients in a New York City men's shelter. American Journal of Public Health 83, 568-570.

Volavka J., Convit A., Czobor P., Douyon R., O’Donnell J. \& Ventura F. (1991) HIV seroprevalence and risk behaviours in psychiatric inpatients. Psychiatry Research 39, 109-114.

Weinhardt L.S., Carey M.P., Carey K.P. \& Verdecias R.N. (1998) Increasing assertiveness skills to reduce HIV risk among women living with severe and persistent mental illness. Journal of Consulting and Clinical Psychology 66 (4), 680-684.

World Health Organisation (2000) Epidemiological Fact Sheet on HIV/AIDS and Sexually Transmitted Infections. WHO, Geneva.

Wright S., Gournay K., Glornay E. \& Thomicroft G. (2000) Dual diagnosis in the suburbs: prevalence, need, and inpatient service use. Social Psychiatry and Psychiatric Epidemiology 35, 297304. 